Cad. Est. Ling., Campinas, 46(2):153-169, Jul./Dez. 2004

\title{
EMERGÊNCIA E FUNCIONAMENTO DAS INTERCALAÇÕES
}

\author{
JULIENE DA SILVA BARROS \\ (UAG/UFRPE)
}

\begin{abstract}
RÉSUMÉ Cet article développe une approche des intercalations - phénomène métaenonciatif qui inclut l'insertion, la digression et la note en bas de page. Cette approche est caractérisée par deux préoccupations spécifiques: en premier lieu, je considére les moments et les formes d'émergence des intercalations dans les textes des élèves - niveau primaire; en second lieu, je propose une systématisation des différents aspects rapportés aux intercalations, comme les formes de notation, les moments d'emérgence, les lieux de matérialisation dans les textes et les fonctions. Ansin, j'aborde le travail du sujet avec l'écriture et les procédures mises en ouvre dans l'énonciation des textes spécifiques.
\end{abstract}

\section{PRELIMINARES}

Neste trabalho, minhas considerações estarão voltadas para aspectos relacionados à emergência e ao funcionamento de fenômenos de interposição como as chamadas inserções, digressões e notas de rodapé - os quais tenho abordado como variações de um processo mais geral chamado intercalação (Barros, 2000) ${ }^{1}$. A intercalação constitui-se tema de minhas reflexões no curso de doutorado e, na tentativa de propor-lhe uma interpretação diferente da que têm feito estudos anteriores, articulo conceitos de duas áreas do conhecimento Lingüística Textual e Análise do Discurso. Ciente das diferenças de interesse e de fundamentos dessas duas áreas e ciente da constitutiva polêmica (constitutiva para ambos os lados) que define as relações entre os dois campos, tenho-me arriscado a descobrir os pontos de contato entre eles. Situando-me nas fronteiras não exploradas por conta dos riscos de invasão de terreno e de influência recíproca, assento minha reflexão nessa linha limite - onde o discurso e o texto negam-se para poderem (a)firmar-se - para explicar as intercalações.

Essa tentativa de interface entre texto e discurso (e entre estudos de texto e de discurso) será percebida nas páginas seguintes, mas não empreenderei uma discussão teórica aqui, pois a questão certamente extrapola os limites deste artigo. Neste texto, observarei apenas um aspecto mais específico relacionado às intercalações, que é sua emergência nos textos escritos da fase de aquisição, numa tentativa de descrever e analisar os momentos e formas

${ }^{1}$ Esse estudo faz parte de uma tentativa ampla de reorientação da concepção desses fenômenos que, tendo sido relegados a um plano marginal nos estudos não enunciativos, permanecem, a meu ver, sem uma análise enunciativa que os contemple adequadamente. Desenvolvi essa argumentação em minha tese de doutorado, defendida em março de 2004, no Instituto de Estudos da Linguagem - Unicamp. 


\section{BARROS - Emergência e funcionamento das}

de emergência, bem como as variações relacionadas aos locais de emergência no texto, às formas de marcação com que são destacadas e reconhecidas, e às funções que preenchem no texto.

Para fundamentar essa análise, adoto, além dos fundamentos gerais que defini para minha tese, que consiste basicamente numa postura de interface na mobilização de conceitos da Lingüística Textual e da Análise do Discurso, o diálogo com os fundamentos específicos do projeto de pesquisa intitulado "A relevância teórica dos dados singulares para a aquisição da linguagem escrita" (Projeto, doravante) ${ }^{2}$. Destaco, desse horizonte, especialmente uma questão de ordem teórico-metodológica: a inspiração num raciocínio inferencial, que se efetiva por meio de um método detetivesco, segundo o qual marcas empíricas são interpretadas como indícios para propor e desenvolver uma análise e não como casos para comprovar uma tese anterior - um modelo epistemológico por Ginzburg (1986) chamado paradigma indiciário.

Numa primeira observação sobre dados da escrita infantil, pude reafirmar intuições anteriores de que as intercalações constituem marcas que podem ser interpretadas como indícios de uma intervenção do sujeito no texto. Esses indícios me permitiram a elaboração da seguinte hipótese geral que guiará a reflexão neste trabalho: a emergência renitente apesar de não autorizada das intercalações coincide com a emergência da subjetividade no texto, sendo, dessa forma, um lugar privilegiado para compreender as primeiras manifestações do trabalho do sujeito em sua relação de constituição recíproca com a linguagem - nesse caso específico, a intervenção do sujeito consistiria numa estratificação ordenada do texto por efeito das intercalações.

\section{EMERGÊNCIA DAS INTERCALAÇÕES}

\subsection{Quando eles (se) intercalam sem saber}

Articulando essa hipótese aos fundamentos mencionados e inspirando-me nas análises realizadas no Projeto, nas quais as pesquisadoras (detetives) buscam (investigam) indícios (pistas) de um trabalho do sujeito (autor emergente?) com a escrita, a partir das reelaborações e outras "marcas" efetuadas em textos da fase de aquisição, buscarei também indícios de um trabalho do sujeito desde as primeiras escritas. Tomarei por base, neste momento, textos das primeiras séries, para introduzir alguns dos muitos aspectos relacionados às intercalações. ${ }^{3}$

${ }^{2}$ Esse projeto é desenvolvido por Abaurre, Fiad e Sabinson, que, em dez anos de pesquisa, vêm contribuindo para a reinterpretação de fenômenos ligados à reescrita na fase de aquisição e, de modo inovador, para o entendimento da constituição do sujeito nos momentos de aquisição dos gêneros do discurso, o que tem direcionado as pesquisas também para questões relativas a estilo. Sem querer sintetizar sua importância, não posso deixar de enfatizar ainda sua contribuição de ordem teórico-metodológica para a pesquisa lingüística em geral e, de modo especial, para minhas reflexões. 
Já nas primeiras observações dos dados, detectei várias intercalações nas primeiras escritas de vários sujeitos, efetuadas de acordo com o que se consideraria suas exigências formais. Mas esses textos me levaram além do que eu me propunha analisar. Eu buscava as primeiras intercalações, por assim dizer, mas encontrei também algo que parece antecedêlas e que - acredito - talvez nelas se transforme no decorrer dos anos. Faço essa suposição porque tenho fortes razões para pensar que muitos dos balõezinhos, quadrinhos, nuvenzinhas, setinhas e tantos outros expedientes que permeiam os textos infantis como meros suportes para recadinhos e similares são, na verdade, indícios das primeiras manifestações de uma necessidade de articular planos diferentes nos textos para separar dizeres específicos (não é para isso que servem as "intercalações adultas"?).

Diante dessa vastidão de dados, resolvi trabalhar com as muitas "intercalações infantis" encontradas considerando inicialmente o que estou propondo designar como intercalações potenciais (ou pré-intercalações, como me sugeriu Raquel Fiad) - aspectos que, mesmo não se constituindo formalmente como intercalações, seriam, tanto pelo propósito enunciativo do que se insere quanto pela exposição diferenciada no texto, potenciais ou futuras intercalações -, deixando para apresentar no próximo subtópico as intercalações efetivas.

Os aspectos que vou destacar nos textos a seguir são "marcas" diversas de uma organização diferenciada do texto, as quais revelam um trabalho do sujeito. Esse trabalho permite interpretar não apenas os rastros do sujeito que enuncia, mas também a consideração, direta ou indireta, da alteridade. Eis um primeiro dado:

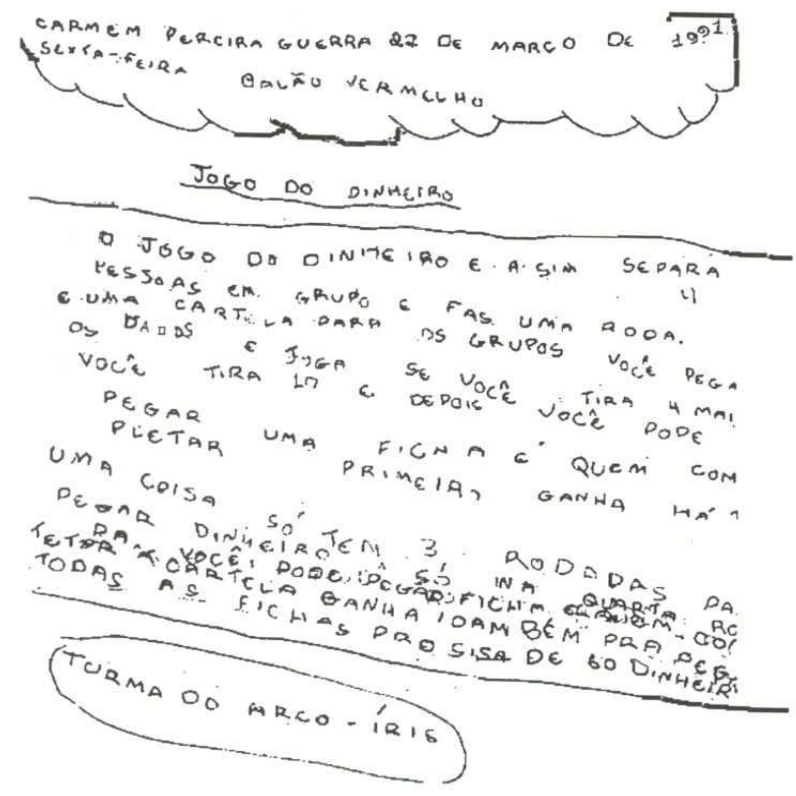

${ }^{3}$ Esses textos são parte do banco de dados do Projeto, o qual se constitui de milhares de textos, organizados em corpora diferentes, como, por exemplo, dois longitudinais com a escrita de sujeitos particulares, além de um terceiro corpus com dados variados, que proporciona estudos de caso, pesquisas transversais, além de outras. 
Nesse texto, há, nitidamente, três subseções (sem contar o título). Inicialmente, a menina desenha uma nuvem para separar uma identificação, fazendo o chamado cabeçalho. No centro, separado ainda por duas linhas, está o chamado texto principal, e, abaixo, separada mais uma vez em um círculo, consta uma segunda identificação. Como transparece ao leitor, essa separação não é gratuita. Não há, no texto de Carmem (1 ${ }^{a}$ série), "invasão de terrenos": cada propósito enunciativo específico se realiza no texto situado em um lugar diferente. Aspectos como estes apontados no texto de Carmem são tão comuns e aparentemente sem segredos que não causam "perplexidade" (para usarmos um termo que adquire um sentido muito especial nas pesquisas de Abaurre) aos analistas. Contudo, mais que constatar aí um "modo infantil" de escrever, chamo a atenção para uma explícita coerência na disposição desse texto.

Essa separação de planos vai assumindo contornos mais explícitos e deixando mais clara a intervenção do sujeito. Não apenas se percebe que ele está no texto por meio de orientações indiretas, digamos, mas por orientações explícitas que evidenciam empiricamente o "eu" e o "outro" com quem dialoga em sua produção textual. No texto a seguir, há uma orientação ao leitor, mostrando não só que Julia ( $1^{\mathrm{a}}$ série) trabalha, mas também que direciona seu trabalho. ${ }^{4}$

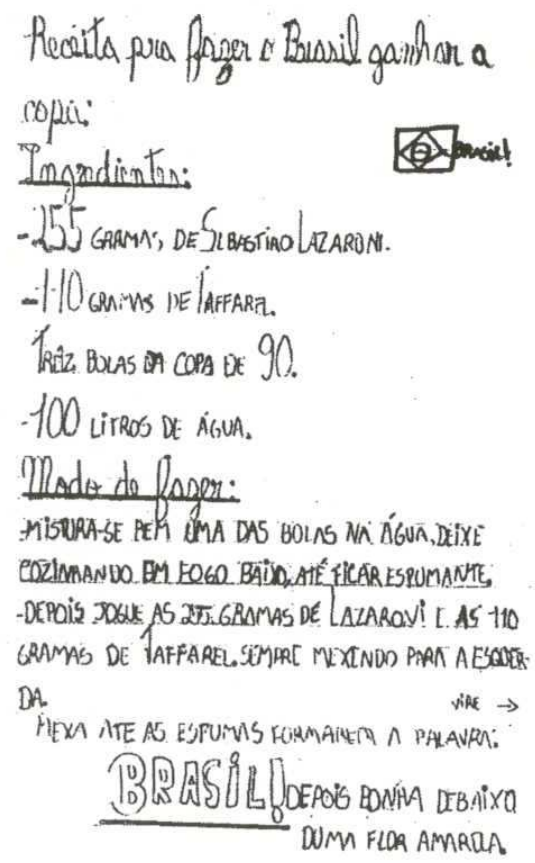

Nesse texto, destaco a orientação escrita, seguida de uma seta: VIRE $\rightarrow$. Essa orientação (que é muito comum em textos escolares) indica a separação do texto, cuja

${ }^{4}$ A análise da representação do outro na escrita infantil é preocupação específica de Mayrink-Sabinson no referido Projeto. 
Cadernos de Estudos Lingüísticos 46(2) - Jul./Dez. 2004

continuação dar-se-á na página seguinte. A advertência direciona o olhar do leitor, e isso parece uma pista de que o sujeito sente a necessidade de organizar sua exposição, ante o fato de a página haver acabado, para que o outro não abandone a leitura. Há uma "saída" do que se vinha tratando e o dizer, VIRE $\rightarrow$, é de outra natureza. O sujeito coloca-se em um outro lugar textual, para, assim, alertar o leitor. Esse gesto metaenunciativo (AuthierRevuz, 1996) faz pensar nos mecanismos de coesão que Koch (1997) denomina sinalizadores textuais, pois há não no plano da coesão local, mas da organização do texto em termos mais amplos, uma nítida sinalização que visa a orientar o interlocutor.

$E$ as interposições dos sujeitos em meio ao que enunciam não se resumem a marcações indiretas ou orientações com propósitos didáticos, digamos. Já nessa fase, os dizeres específicos dos alunos vão muito além disso, pois é possível observar também a interposição de outros atos de fala, cuja natureza revela questões afetivas, cognitivas.
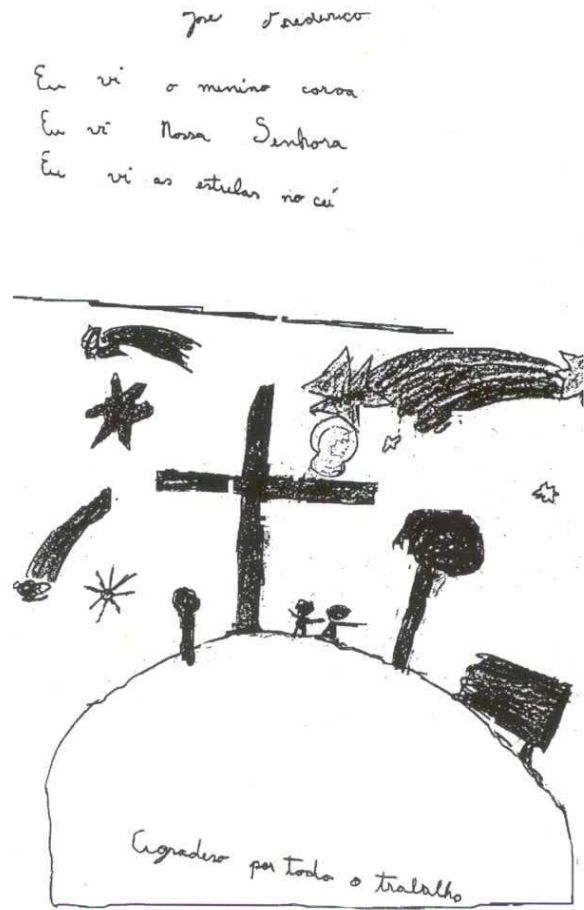

José Frederico ( $1^{\text {a }}$ série), mesmo escrevendo um chamado texto de cartilha, separa cuidadosamente os planos verbal e não-verbal e, abaixo, ainda dirige-se à professora, num "agradesimento" pelo trabalho realizado. Quantas vezes nos textos acadêmicos e outros são feitos agradecimentos, ressalvas e comentários deslocados dos textos. Basta ver, por exemplo, que, em artigos científicos, os agradecimentos direcionados às instituições de fomento são devidamente colocados na chamada posição de rodapé. Sem querer dizer que o aluno da primeira série age a partir das mesmas motivações e constrições que um pósgraduando, ou, indo mais (pro)fundo, sem querer dizer que é o mesmo agradecimento, 
pode ser dito que há uma efetivação do ato de agradecer tanto em um momento quanto em outro, num espaço textual específico.

Os diferentes aspectos destacados revelam que, mesmo antes de fazerem intercalações efetivas, os meninos e meninas já fazem uma separação multilinear de sua enunciação. Eles estratificam (ainda de um modo meio artesanal) o dizer, de acordo com os propósitos enunciativos que têm. Assim, mesmo antes de intercalarem de fato, eles fazem o que estou interpretando como intercalações potenciais, com base na hipótese de que servem a propósitos semelhantes aos das intercalações efetivas. E esse trabalho do sujeito indicia tanto a assunção de si quanto a do outro em suas relações com a linguagem escrita. Em meio à textualização disso, destacam-se os primeiros bons ensaios de produção textual. São textos, inscritos, a seu modo, na situação histórica que os circunda, coerentes, coesos, que comprovam, desde muito cedo, o que se discute a respeito dos componentes textuais e discursivos que estão envolvidos no processo de constituição dos sentidos

\subsection{Quando eles já sabem que (se) intercalam}

Se ao efetuarem intercalações potenciais os sujeitos já revelam suas intuições em relação à textualização de propósitos enunciativos, especialmente no que toca à exposição diferenciada e ordenada desses propósitos, mais claros se tornam os indícios do desenvolvimento dessa competência quando efetuam intercalações efetivas. Mais que um modo artesanal de intercalar, verifica-se já uma exploração sistemática das intercalações várias, pois usam - e com sofisticação - parênteses, vírgulas, e, até mesmo, notinhas de rodapé. Assim, eles não apenas deixam seus rastros em meio ao texto, pela estratificação que fazem, ou não apenas dependuram-se, antecipam-se ou anexam-se de modos vários na perigrafia textual, como também entram efetivamente na escrita quando intercalam (-se), delimitando um terreno que é do sujeito: é deles - pequenos sujeitos escreventes de textos.

Passarei rapidamente por alguns textos raros das primeiras séries do Ensino Fundamental. Sujeitos na mesma idade escolar dos que escreveram os textos mostrados no subtópico anterior, realizam intercalações várias, tal como o fazem os chamados escritores proficientes. Observemos um primeiro texto.
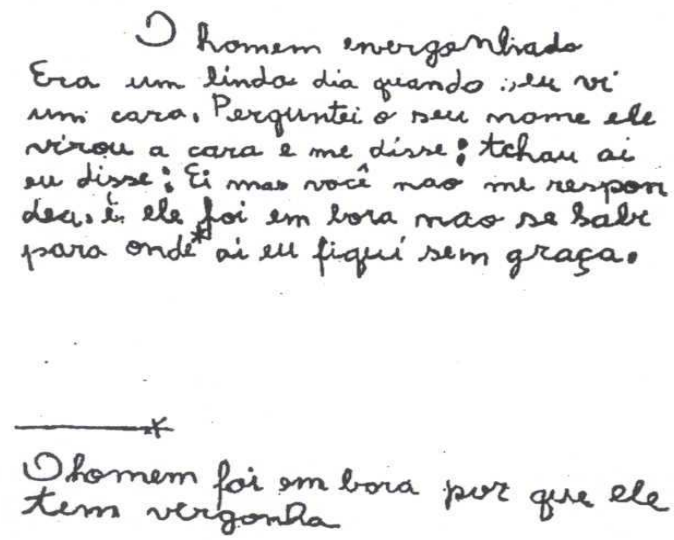
O texto de Maria Lucia - ML $\left(2^{\mathrm{a}} \text { série }\right)^{5}$ constitui um dado raro. Não encontrei (e certamente não encontrarei com facilidade em outros lugares), notas de rodapé, efetuadas de modo sistemático, com indicação remissiva - o asterisco repetido -, na segunda série. Esse dado causa perplexidade tanto pelo que revela a natureza do conteúdo deslocado (o propósito enunciativo) como pela sofisticação formal - que, certamente, é raríssima nessa idade escolar ${ }^{6}$. Observe o leitor que, no tópico anterior, as intercalações potenciais que se encontravam deslocadas eram do tipo antecipações ou PS (Post Scriptum), algo que, embora se voltasse sobre o texto, referia-se a ele como um todo, ou a seu exterior (quando os alunos dirigiam-se à professora). Aqui, sem deixar de mostrar o sujeito e seu diálogo com o outro, a notinha aponta para uma questão específica - qual seja, a justificativa para o homem ter ido embora ("O homem foi embora porque ele tem vergonha"), direcionada precisamente ao ponto do texto em que ela narra a fuga desse mesmo homem.

Longe estamos de um "defeito textual"; longíssimo, de um "conteúdo sem relação" pois, nesse sentido, há não só a articulação precisa a um ponto do texto, como também uma explícita coerência com seu título. Não me furtaria a admitir que, para o leitor adulto (e buscador de essências), essa intercalação pudesse ter um efeito acessório, justamente por conta do título; mas, para a menina que a efetua, a nota certamente resolve uma necessidade de explicitude, não sendo, de modo algum, "um acréscimo contingente" (se o dialogismo é fundante e a coerência contextualizável, não se pode, por um lado, excluir um dos pares da relação - o leitor - e julgar o fenômeno aprioristicamente como acessório; e, por outro, conceber um suposto leitor único, que dispensaria a nota para a compreensão do texto, e dizer que é desnecessária). ML, com esse gesto (que não é único em seus dados, como mostrarei adiante), dá um testemunho precioso de que as intercalações emergem de acordo com as necessidades enunciativas, desde as primeiras escritas e justificam sempre sua razão de ser.

O texto a seguir, que é também de ML, mostra esse uso justificado da intercalação, desta vez com interposições feitas tanto no continuum como na perigrafia textual.

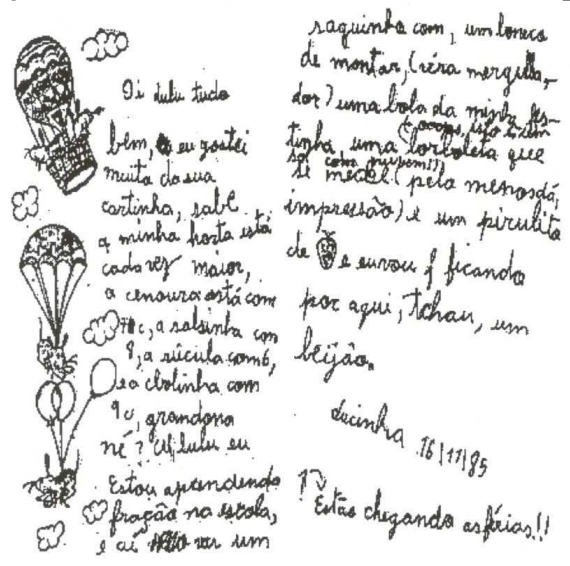

${ }^{5}$ Esse texto foi analisado por Abaurre (1997) e muito do que dele direi já fora tratado por esta pesquisadora.

${ }^{6}$ Não estou querendo dizer que ela já saiba da sintaxe, da semântica e da pragmática de um texto; estou dizendo mais: ela sabe texto. E, claro, as intercalações de seus textos não caem do céu; é uma leitora, não apenas escrevente, e, aos poucos (ou aos muitos?), vai internalizando a "gramática da intercalação" e desenvolvendo 
Iniciarei minhas considerações pela perigrafia desse texto, voltando posteriormente ao continuиm, pois quero aproveitar o gancho para tentar propor uma diferença entre dois fenômenos que às vezes são confundidos. ML (agora, na $3^{\text {a }}$ série) termina seu texto com

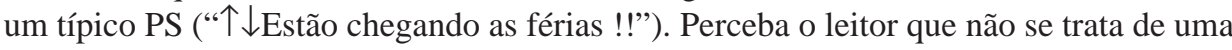
nota efetiva, tanto porque não tem marcação remissiva ao texto, como porque não se direciona a um ponto específico: trata-se de algo, que, embora tenha a ver com o texto todo, é, como se diria, um adendo, post scriptum. Isso interessa para pensar nos muitos autores que - de diferentes lugares teóricos! - chamam notas de rodapé de "acréscimos contingentes", "adjunções de conteúdos descentrados". A nota não é acrescida ao texto, nem mesmo a chamada nota de fim de capítulo, posto que se origina e, portanto, se remete a um lugar específico - a nota (como as outras intercalações) é uma especificação de um ponto do texto; já o PS pode ser lido como acrescido, não devendo esse acréscimo ser julgado a priori como contingente ${ }^{7}$.

Não é contingente como não são as interposições feitas no continuum desse mesmo texto. ML faz três intercalações no corpo do texto, todas limitadas por parênteses. A primeira explica que o boneco de montar vira mergulhador; a segunda faz uma paráfrase do conceito de borboleta, quando a escrevente dá-se por conta (“ooops"...) - posteriormente, pois os parênteses estão sobrepostos -, que se trata de "um sol com nuvem" (talvez a borboleta tenha sido desenhada a partir da junção de um sol e de nuvens, mas não dá para saber ao certo; a não ser que ela faz uma reformulação retórica e não uma correção: ML não apaga, não exclui a borboleta, deixando que se leiam simultaneamente as duas idéias) ${ }^{8}$; a terceira (única ocorrência desse ato de fala nessa série em todo o corpus pesquisado) é uma ressalva - "pelo menos dá impressão" (de que a ambígua borboleta se mexeria...).

Além da emergência de intercalações marcadas por parênteses, notas de rodapé e PS, é possível encontrar nos textos infantis também intercalações marcadas por travessões e, até mesmo, por marcadores verbais, como os marcadores de paráfrase.

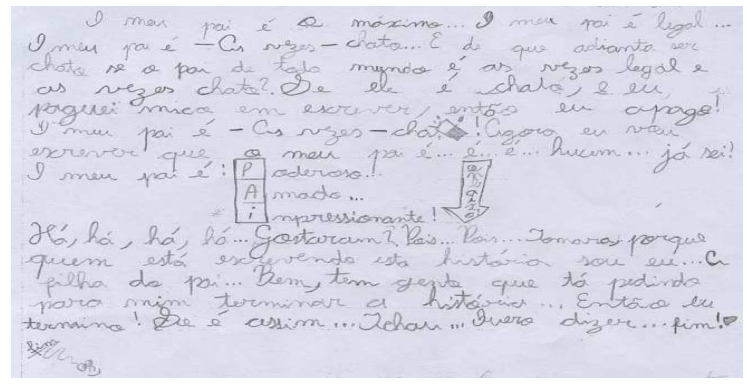

sua "competência" para usá-la apropriadamente em lugares igualmente apropriados.

${ }^{7}$ Não estou dizendo que a nota não possa ser inserida após uma re-leitura, após o texto haver sido escrito. O que contesto é ela ser tida como mero adendo. Como mostra o dado de ML, a nota surge de um ponto e se volta sobre esse ponto, especificando-o. A consideração de adendo despenca rapidinho para acessório, irrelevante...

${ }^{8}$ Basta que o leitor observe o caso, já analisado por Abaurre (1997), da substituição "vai/vão", onde a criança efetivamente corrige, substituindo uma forma pela outra. No caso, as idéias de borboleta e sol com nuvem sobrepõem-se - literalmente! 
Cadernos de Estudos Lingüísticos 46(2) - Jul./Dez. 2004

Neste texto de Raquel merece destaque o uso dos travessões. Ao falar do pai, a menina afirma na segunda linha. "O meu pai é - às vezes - chato". A afirmação de que o pai é "às vezes" chato é posta cuidadosamente entre travessões, num caso em que costumeiramente se usaria a vírgula. Ocorre que, desde as gramáticas tradicionais, destaca-se que a vírgula pode ser substituída pelos travessões em casos onde se deseja dar ênfase. E Raquel parece querer enfatizar que seu pai é apenas às vezes chato, porque, além de destacar essa ressalva, arruma uma solução bastante inteligente para nem isso ter de dizer dele. Se todos os pais seriam, segundo ela, às vezes legais e às vezes chatos, é "mico" repeti-lo, como ela diz, de modo que prefere apagar - e apaga. Desenha uma borracha em movimento do fim para o começo da frase e a apaga, para dizer o que seu pai realmente é, num acróstico (PAI: Poderoso, Amado, Impressionante). Além desse uso justificado do travessão, merece destaque o último parágrafo do texto, onde Raquel personaliza o marcador de paráfrase, "quer dizer", possivelmente para corrigir uma inadequação na forma de finalizar o texto:"Tchau, quero dizer, fim" - o que pode ser interpretado como uma busca de adequação ao estilo do gênero (Bakhtin, 1979).

As formas de marcação e as funções variadas das intercalações permitem considerar, que, mesmo essas intercalações sendo fruto de uma clara pressão da própria enunciação no texto (pois esses dizeres preenchem necessidades do texto, ligadas a constrições da própria enunciação e não apenas veleidades dos pequenos sujeitos), não vejo por que nem como negar que há um trabalho do sujeito. Assim, esses dados são suficientes para desenvolver a idéia de que as intercalações são fenômenos privilegiados para se observar a constituição da subjetividade entre controles e pressões e o trabalho do sujeito com o texto. Proponho, portanto, uma primeira hipótese explicativa, a qual amplia meu ponto de partida: uma intercalação é o resultado de uma interposição do sujeito, que constitui um plano enunciativo interposto e sobreposto, o qual instaura níveis enunciativos especificados, exigindo, portanto, formas de dizer igualmente específicas.

Essa interposição do sujeito, pelos aspectos diferentes que mobiliza, pode revelar tanto a organização do texto quanto a constituição do próprio sujeito e talvez, justamente por isso, podem ser detectados, no trabalho com as intercalações, os primeiros indícios de autoria nos textos (Possenti, 2002). Mas não quero tratar de autoria referindo genericamente o trabalho do sujeito - isso a teoria linguiística vem destacando há muito tempo como marcas do sujeito no texto. Autores como Benveniste, Jakobson, Ducrot e outros, ainda dentro do Estruturalismo, já apontavam marcas pelas quais o sujeito se mostra, sem que a isso chamassem autoria. Atualmente - em alguns lugares - "as coisas voltam a ser o que sempre foram", pois cada vez mais se vêem trabalhos sobre a "autoria", em que o suposto autor desenhado reflete facilmente o sujeito, o locutor, o enunciador e, se se procurar direito, até o emissor... Esse conceito precisa ser pensado cuidadosamente, indo além de uma troca de nomes. Voltarei ao tema num próximo trabalho. 


\section{FUNCIONAMENTO DAS INTERCALAÇÕES}

\subsection{Formas, momentos de emergência e funções}

Contemplados brevemente alguns dos muitos aspectos envolvidos com a emergência das intercalações, a partir da discussão de alguns dados, passarei a uma abordagem mais específica que visa a sistematizar alguns dos aspectos envolvidos, explicitando os modos de funcionamento das intercalações nos textos em que emergem. Para encaminhar essa discussão, farei uma primeira tentativa de sistematização, de acordo com a qual buscarei captar os momentos e as formas de emergência e as razões por que os pequenos sujeitos intercalam. Mesmo um estudo de base qualitativa não dispensa procedimentos como classificações e descrições, se os resultados fornecidos por estas servirem como argumentos a favor da análise que propomos. Usarei aqui critérios elaborados em trabalhos anteriores (Barros, 2000, 2001). Inicialmente, lançarei mão de um critério de posição, para classificar as intercalações em presentes no continuит textual ou deslocadas para a perigrafia (que inclui, não apenas a posição de rodapé, mas o cabeçalho e as laterais do texto). Dentro desse critério, trabalhei com um outro - de centração -, para dar conta dos possíveis efeitos de afastamento do propósito geral do texto, e, por tal critério, categorizo - provisoriamente - as intercalações em digressivas e não digressivas ${ }^{9}$. Embora meu interesse seja com as séries iniciais, observarei textos das demais séries do Ensino Fundamental para estabelecer elementos de comparação e melhor situar a discussão nas primeiras séries. Nas primeiras seis séries, trabalharei com 100 textos de cada, nas séries seguintes o número de textos será reduzido a setenta, por não haver quantidade similar nos dados selecionados. Abaixo constam quadros-síntese que mostram as formas de disposição e a frequiência de acordo com as séries.

\subsection{Formas de disposição e freqüência de acordo com as séries}

1.1. Primeiros ciclos do fundamental

\begin{tabular}{|c|c|c|c|c|c|}
\hline TIPO & & PRES & NTE & & SLOCADA \\
\hline & ○ & digressiva & $\begin{array}{c}\text { não } \\
\text { digressiva }\end{array}$ & digressiva & $\begin{array}{c}\text { não } \\
\text { digressiva }\end{array}$ \\
\hline $1^{a}$ série & 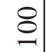 & -- & 09 & -- & 19 \\
\hline $2^{a}$ série & 의 & -- & 30 & -- & 20 \\
\hline $3^{\text {a }}$ série & 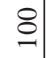 & -- & 13 & -- & 08 \\
\hline $4^{a}$ série & ఏ & -- & 16 & -- & 09 \\
\hline
\end{tabular}

${ }^{9} \mathrm{Na}$ verdade, esse critério tem uma utilidade apenas indireta neste trabalho, pois as chamadas intercalações digressivas, reconhecidas como digressões, são a base de alguns dos descasos do ensino e da teoria com essa questão - o efeito de afastamento depõe contra o fenômeno por conta do risco da descontinuidade sintática e da fragmentação textual. 
Cadernos de Estudos Lingüísticos 46(2) - Jul./Dez. 2004

1.2. Segundos ciclos do fundamental

\begin{tabular}{|c|c|c|c|c|c|}
\hline \multirow{2}{*}{ PERÍODO } & \multirow{2}{*}{ ర్త } & \multicolumn{2}{|c|}{ PRESENTE } & \multicolumn{2}{|c|}{ DESLOCADA } \\
\hline & & digressiva & $\begin{array}{c}\text { não } \\
\text { digressiva }\end{array}$ & digressiva & $\begin{array}{c}\text { não } \\
\text { digressiva }\end{array}$ \\
\hline $5^{\mathrm{a}}$ série & 8 & -- & 37 & -- & 11 \\
\hline $6^{\mathrm{a}}$ série & 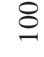 & -- & 35 & -- & 07 \\
\hline $7^{\mathrm{a}}$ série & 8 & -- & 27 & -- & 04 \\
\hline $8^{\mathrm{a}}$ série & 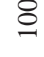 & -- & 26 & -- & 03 \\
\hline
\end{tabular}

Não irei analisar esses quadros em detalhes. Meu objetivo é apresentá-los ao leitor e tirar algum proveito de questões apontadas nos números para encadear minha reflexão adiante. Dessa forma, destacarei alguns pontos. Esses quadros parecem dizer pouco em termos quantitativos, se tivermos em mente que esse tipo de análise deve apontar tendências, evoluções, enfim, permitir estatísticas sobre as variáveis que levem a generalizações. Claro que parece haver certos movimentos ascendentes ou descendentes de acordo com as séries, mas isso não é contínuo, nem linear. Há números inesperados, como os da segunda série, cuja possível tendência, um aumento, embora confirmada nas séries seguintes, mostra um salto quantitativo desproporcional em relação às demais séries (o que pode ter a ver com o estilo do gênero em que tais intercalações emergem). Além dessa primeira imprecisão, reconheço que há, mesmo dentro de movimentos ascendentes ou descendentes, diferenças muito pequenas, as quais precisariam ser revistas para que pudessem ser assumidas de fato como tendências.

De qualquer forma, é possível, a partir dos números, apontar algumas questões de interesse. Além de destacar a constância de intercalações em todas as séries e a variação entre presentes e deslocadas, é interessante falar de modo mais detalhado em três outras questões - as duas últimas quase óbvias. Primeira: não foram encontradas - o que não significa que não se faça -, em nenhuma das séries, o que estou chamando intercalações digressivas (costumeiramente chamadas digressões) - isso é interessante para se pensar que, se grande parte do descaso do ensino com as intercalações dá-se porque elas são vistas como digressões, sinônimas de desvio de tópico, divagação etc, essa questão pode começar a ser repensada: as intercalações dos alunos não são digressivas (e se fossem mereceriam estudo e não descaso $)^{10}$. Segunda: há um aumento progressivo da freqüência

${ }^{10}$ Mantive o critério e a categoria analítica, sem a realização da variável, para marcar a ausência, justamente. Em minha tese, revejo essa categorização. 


\section{BARROS - Emergência e funcionamento das}

de intercalações presentes não digressivas ao longo das séries - o que parece um sintoma de maior número de leituras e da aprendizagem dos modos de intercalar e, por outro lado, um amadurecimento sintático e textual que faz com que os alunos tenham um domínio maior das possibilidades de intercalar. Terceira: é notada uma diminuição progressiva das intercalações deslocadas não digressivas ao longo das séries - o que parece uma contraparte da questão anterior: com o amadurecimento sintático e textual (e também pela idade...), os alunos começam a intercalar com mais propriedade no corpo do texto, dispensando os quadrinhos, nuvenzinhas e outras, passando a usar outras formas. Mas não gostaria que essa tendência levasse à idéia de que nas últimas séries não há intercalações deslocadas. ${ }^{11}$ Fecho, por um momento, essa discussão para tratar de outros aspectos.

\subsection{Formas de marcação}

Apresentarei uma síntese dos modos como os sujeitos marcam as intercalações que fazem em seus textos. Os dados permitem detectar marcadores bem variados. Trabalharei com três categorias principais, que buscam dar conta das formas de marcação - conforme sejam verbais, não-verbais ou combinadas em verbais e não-verbais. Dentro dessas três categorias, observarei os marcadores específicos, por meio dos quais são destacadas as intercalações. Dentre os marcadores verbais, incluo não apenas os bracketing devices (marcadores conversacionais), mas também os verbos dicendi, ou verbos de elocução que não são tratados dessa forma na literatura. Os não verbais incluem, além de parênteses, vírgulas e travessões, outros marcadores não oficiais como balões, quadros, nuvens, asteriscos, setas, mudança de cor, etc. A marcação combinada leva em conta não apenas marcadores não-verbais ou verbais diferentes, mas também verbais combinados com nãoverbais e vice-versa, como pode ser visto a seguir.

${ }^{11}$ Não posso deixar de reconhecer que o número diferenciado de dados pode ter interferido na análise. Mas não garantiria que o número igual por série proporcionasse tendências diretamente ou inversamente proporcionais. O número de textos não pode ser a única variável envolvida para analisar essa questão. 
Cadernos de Estudos Lingüísticos 46(2) - Jul./Dez. 2004

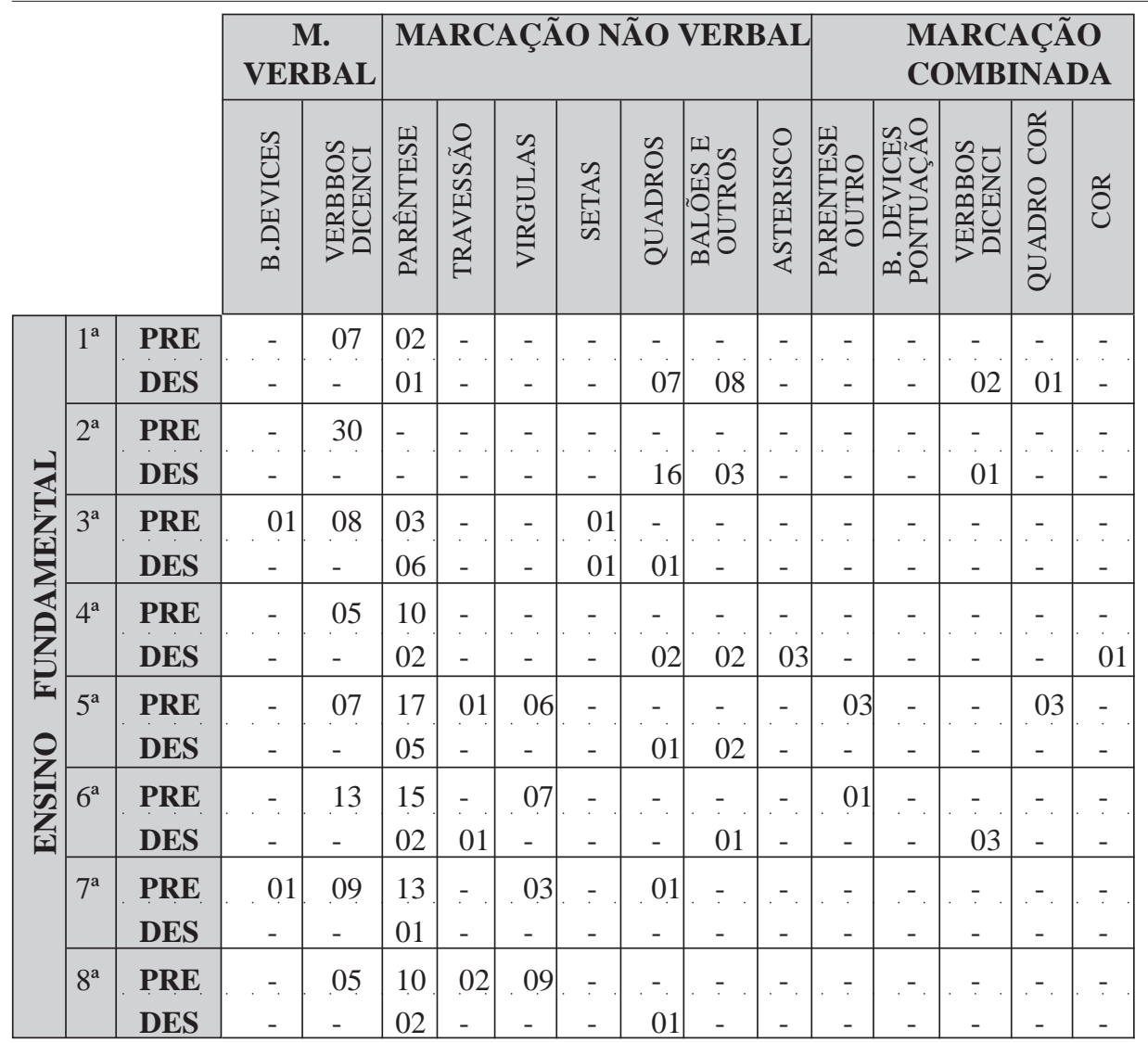

Em relação a esse quadro, gostaria de destacar também algumas questões - sem pretensão de que isso seja lido como conclusão, mas apenas como resultados circunstanciais, devidos à metodologia aplicada. Assim, privilegiarei alguns pontos (que podem não ser os mais importantes). Inicialmente, destacaria a recorrência de marcadores como os parênteses e os verbos dicendi, desde as primeiras séries até as últimas séries do fundamental - são os marcadores mais característicos e é normal que eles apareçam e recorram. Outro fato destacável é a quantidade grande de balões e quadros nas séries iniciais e o progressivo desaparecimento desses sinais nas últimas séries - isso sugere não apenas que os alunos vão deixando as formas infantis de intercalar, mas também que essas formas ou migrarão para o continuиm textual ou, possivelmente, se transformarão em notas de rodapé. Aliás, balões e quadros deslocados, e o conteúdo que neles se insere, mostram os primeiros ensaios das futuras notas de rodapé. Outra questão digna de nota é o fato de praticamente não aparecerem nas séries iniciais marcadores como os $b$. devices e travessões e, de certa forma, até mesmo a vírgula - o que pode ter a ver com o amadurecimento sintático e textual exigido no uso de tais marcadores. Especialmente os b. devices, só os encontrei na última série do segundo grau, e em quantidade pequena, o que pode ser explicado assim: a 
atitude de suspender verbalmente a enunciação para efetuar uma excursão maior exige cálculo e um certo controle, sob pena de não haver retorno ao que se tratava anteriormente. Outro aspecto interessante a destacar é a presença, já nas séries iniciais, de marcações combinadas. Esse tipo de marcação é encontrado em textos de adultos e foi surpreendente ver que, a seu modo (e não sei se a exploração é deliberada), as crianças já fazem uso dessa marcação.

\subsection{Formas enunciativas constituídas}

Vistas as formas de marcação, uma importante questão é mostrar a que propósitos servem as intercalações feitas. Como as intercalações aparecem, já mostrei; mas por que os alunos as fazem, não - exceto nos poucos casos discutidos anteriormente. Responder a esta questão é um passo fundamental para pensar o funcionamento das intercalações. São as funções desempenhadas que poderão responder a que propósitos elas servem e por que razões as crianças as fazem, mesmo que não conheçam das questões formais envolvidas em seu uso. Na primeira tentativa de análise, pude notar funções que constituem formas enunciativas diversas.

Por meio de intercalações, presentes e deslocadas, são constituídas identificações, anaforizações, dedicatórias, traduções de termos, explicações, reformulações, correções, definições, avaliações, ironias, citações, ressalvas, especificações, alusões, além de marcar datas, orientar a leitura, indicando páginas seguintes ou anteriores, dentre outras. Advirto, contudo, que a nomeação dessas funções é devida a uma interpretação, ao modo como entendi os propósitos que as intercalações preenchiam nos textos analisados; mas um outro analista poderia interpretá-las diferentemente. Uma outra advertência é que não é meu interesse primordial elencar funções particulares; na verdade, sempre critiquei (e critico) a atitude dos gramáticos - e de outros - que se prendiam a funções específicas e não ultrapassavam os dados em si, esbarrando no produto sem compreender o processo.

Mas, se em outros trabalhos não considerei primordial enumerar funções específicas, aqui - interessante - essa é uma questão crucial, porque explica a emergência e serve para engatar um rediscussão a respeito das intercalações no ensino, onde, de maneira geral, sobrevive um discurso, em cuja base se pode ler uma condenação ao uso das intercalações. ${ }^{12}$ As funções justificam o uso, afastando a idéia de que seriam defeitos textuais. Eis, portanto, algumas das formas enunciativas constituídas pelas intercalações.

${ }^{12}$ Digo apenas no ensino, porque as pesquisas em Lingüística Textual e Análise do Discurso têm promovido análises importantes sobre as intercalações, as quais em muito avançam em relação aos estudos tradicionais mesmo que permitam (e não seria bom se não permitissem) novos questionamentos e propostas explicativas. Meu olhar para o ensino é porque constituo como outro dessa reflexão a gramática, que é, nesse caso e talvez em outros, quem tem influenciado o trabalho com as intercalações na escola. 


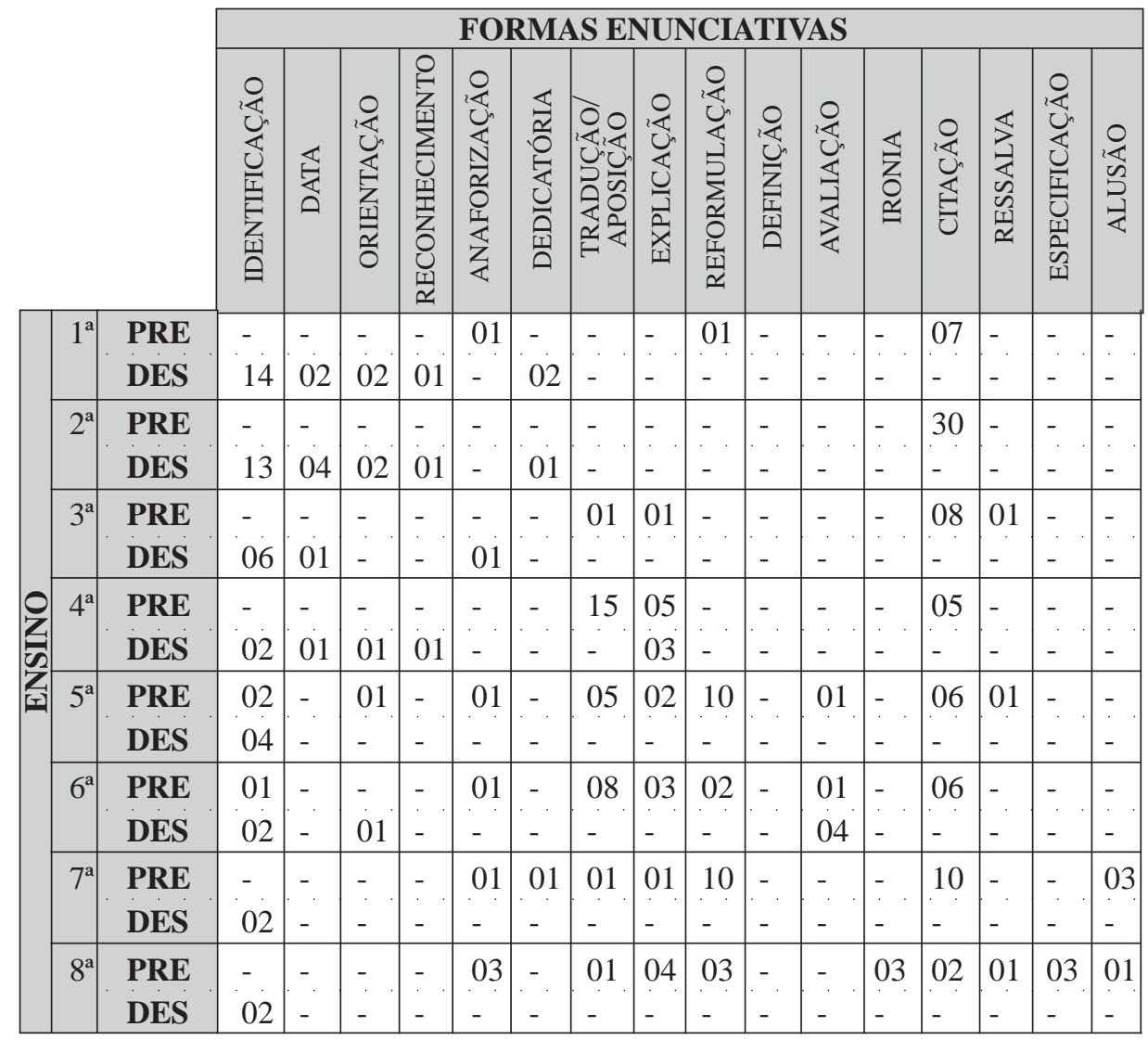

Sobre essa tabela, é importante mostrar que as intercalações encontradas nos textos dos alunos preenchem desde funções mais simples (não estou opondo simplicidade à importância, mas à complexidade), como identificações, citações e datas, até anaforizações, aposições - sobretudo à medida que a competência textual(-discursiva) vai se desenvolvendo.

É curioso ver crianças de $4^{\mathrm{a}}$ série efetuando ressalvas. Quem as ensinou? Quem lhes ensinou mecanismos pragmático/discursivos de preservar a face, antecipar defesas, anular contra-argumentos? Desde quando esses meninos e meninas sabem que um texto tem propósitos gerais que precisam ir sendo especificados localmente por meio de atividades cognitivas e atos de fala particulares? Desde quando esses meninos e meninas sabem que quando se interfere na sintaxe, é preciso fazê-lo em forma de bloco (daí os pares de vírgulas, de travessões, de parênteses), para que se retome a estrutura sintático-semântica do período? Não quero sugerir que as crianças nasçam sabendo, mesmo que não saibam que sabem. Mas é apenas a condição de leitor que faz o aluno aprender a intercalar? E, não mais do ponto de vista da aprendizagem, mas dos efeitos, como pensar que aquilo que os alunos 
intercalam é mero acréscimo contingente, que perturba a sintaxe, desviando os tópicos e causando defeitos textuais?

Não está nas pretensões desse trabalho responder em específico a cada uma dessas questões, mas, sem dúvida, todas elas são relacionáveis numa possível explicação, já que se colocam simultaneamente quando se pensa as intercalações. Assim, mesmo sem haver solução imediata, é possível, com base nesses questionamentos, a proposição de uma segunda hipótese explicativa, acrescentando novos elementos à primeira: as intercalações são fenômenos enunciativos, resultantes de uma interposição do sujeito, cuja emergência exige, para ser textualizada, uma competência textual-discursiva (em suas dimensões sintáticas, semânticas, pragmáticas), que se desenvolve não apenas pela prática de escrita, mas também pela de leitura. Essa hipótese é devida à observação também do funcionamento, pois este explica a emergência, afastando a idéia de que as intercalações seriam a "doida da casa" (instâncias dionisíacas por definição...).

Resta dizer que, por meio das intercalações, os sujeitos voltam-se sobre o próprio texto, sobre si mesmo, sobre o já-dito, projetam-se em direção ao outro, ao não-dito. Essa atitude, por Jaqueline Authier (1986) chamada metaenunciativa, constitui-se como um retorno do sujeito sobre a linguagem, o qual considero - em todos os casos e em grau maior ou menor - uma intervenção do sujeito e uma pressão discursiva. Conquanto pareça que agem por mera antecipação ou retomada, no sentido de sanar problemas relativos à decantada incompletude textual, agem mesmo é porque essa premente incompletude os pressiona desde muito cedo a considerar as possíveis e inúmeras fissuras do sujeito e da linguagem. É certo que não se revela, nos textos das crianças, um grande aparelho ideológico, ou uma instituição com dispositivos explícitos, mas talvez não se possam negar indícios de uma micro-física de poder, cuja atuação se materializa por sutis e disfarçados efeitos de constrição, que fazem a ação do sujeito ser um emergir em meio a pressões e não mera deliberação. Eé aí, pela linguagem, pelo texto mais precisamente, que os sujeitos emergem numa arena entre liberdade individual e pressões exteriores.

\section{PERSPECTIVAS}

Não tenho conclusões além das hipóteses explicativas que elaborei localmente, em diferentes pontos desse texto. Apresentarei algumas perspectivas que se abrem a partir desse olhar para a escrita inicial (e indicial) e dessa primeira tentativa de análise. Sobre ganhos de natureza teórica, destacaria as vantagens em se adotar um modo de raciocínio inferencial, inspirado no paradigma indiciário, para as pesquisas em texto e discurso e, de modo específico, para minha pesquisa, onde promovo uma interface, propondo como objeto o texto-discurso.

No que respeita a contribuições de natureza teórico-prática, destaco que a partir de um olhar que mostre a recorrência, a forma de disposição e de marcação, as funções mais específicas e as implicações dessas questões para a aquisição dos gêneros e a constituição da autoria, é necessário - e urgente - que seja rediscutido o estatuto residual, sem importância e prejudicial desse fenômeno na escrita escolar. A discussão do estatuto das intercalações pode levar a vê-las não mais como dados residuais, nem ocasionais, mas como dados 
Cadernos de Estudos Lingüísticos 46(2) - Jul./Dez. 2004

singulares - duplamente singulares: primeiro, são singulares por não caberem nem serem previstos nas explicações sintáticas e textuais que, nesse caso, servem de base ao ensino; segundo, porque mostram que muito longe estão de serem meras impropriedades textuais ou sintáticas, sendo, diferentemente, um lugar privilegiado para se pensar a relação do sujeito com a linguagem, um lugar da constituição da singularidade. Um lugar em que os sujeitos (desde sujeitinhos) metaenunciam, voltam-se sobre o próprio texto, ou dirigem-se a um interlocutor e, para tanto, usam lugares e recursos formais específicos.

Por fim, se a teoria encarar esses fenômenos de modo que eles possam ser analisados coerentemente, sem se pautar em julgamentos superficiais que desconsideram sua natureza, sua constituição e as variações, poderá dialogar com o ensino, abrindo possibilidades de esclarecimento e de trabalho com essa questão. E quando digo isso, não quero sugerir que a escola deva "ensinar intercalações"; acredito no ensino do texto, na tematização dos gêneros: essas outras questões passam pelo texto, fazem-se no texto. Assim, inspirandome em Moreli, que fez novas atribuições de obras de arte nos museus da Europa por meio de um paradigma indiciário, quero contribuir para um reenvio das intercalações, que vêm sendo tratadas como marginais por estudos não enunciativos, para um lugar teórico em que possam ser explicadas e, ao lado disso, contribuir para uma melhor compreensão desse tema no ensino.

\section{REFERÊNCIAS BIBLIOGRÁFICAS}

ABAURRE, M. B. M.; R. S. FIAD \& M. L. T. MAYRINK-SABINSON. (1997). Cenas de aquisição da escrita: o trabalho do sujeito. Campinas: Mercado das Letras.

AUTHIER-REVUZ, J. (1984). "Heterogeneidade(s) Enunciativa(s)". Caderno de Estudos Lingüísticos. № 19, IEL-Unicamp, (trad. de Hétérogeneité(s) énonciative(s), 73, Paris Larousse, Langages) pp. 25-45.

BAKHTIN, M. (2000). Estética da criação Verbal. 1979. São Paulo: Martins Fontes.

BARROS, J. (2000). "Digressão: fragmentação ou estratégia discursiva?". Resumo publicado no V Congresso de Filologia. Rio de Janeiro. (2002). "Intercalação, metaenunciação e autoria". Revista Leitura. № 2. Ufal.

GINZBURG, C. (2000). Mitos, emblemas e sinais: morfologia e história.1986. São Paulo: Companhia das Letras, $4^{\mathrm{a}}$ ed.

KOCH, I. G. V. (1998). O texto e a construção dos sentidos. São Paulo: Contexto.

POSSENTI, S. (2002). "Indícios de autoria”. In Perspectiva - Revista do Centro de Ciências da Educação, 20 (1) (expressão da língua portuguesa e seu ensino). Florianópolis, Editora da UFSC, pp. 105-124. 